\title{
Carencias en nuestro equipamiento colectivo
}

POr JAVIER GOROSQUIETA

Ante declaraciones reiteradas de los responsables de la politica económica española, que manifiestan el propósito de que el 111 Plan de Desarrollo mejore proporcionalmente más el equipamiento colectivo que los ingresos individuales, es mi intención ofrecer algunos datos que ayuden a formarse una imagen sobre la situación actual en nuestro pas en materia de equipamiento comunitario. Tales datos confirman plenamente la oportunidad de esa orientación comunitaria del III Plan.

\section{Hacinamiento}

El porcentaje de hogares con dos o más personas por habitación es el siguiente en las provincias más afectadas:

Cádiz, 29 por 100; Sevilla, 16 por 100; Córdoba, 15 por 100; Las Palmas, 27 por 100; Málaga, 15 por 100.

\section{Agua corriente}

El porcentaje de hogares sin agua corriente es el siguiente en las provincias más afectadas:

Orense, 80 por 100; Cuenca, 75 por 100; Soria, 74 por 100; Pontevedra, 63 por 100; Lugo, 61 por 100; Badajoz, 61 por 100 .

\section{Analfabetismo}

El porcentaje de hogares con el cabeza de familia analfabeto es el siguiente en las provincias más afectadas:

Huelva, 23 por 100; Jaén, 22 por 100; Málaga, 21 por 100; Códoha, 20 por 100; Granada, 20 por 100. 
Sólo corresponden en nuestro pais cuatro camas por módico proporclón que superan la mayoria de los paises europeos e lberoamericanos. De esta situación se desprende una acción futura bas. tante clara: o se crean más puestos hospitalarios en España, o de nuestro pais tendrá que emigrar un gran contingente de médicos a otros paises de Europa, América o Africa.

Por otra parte, nada menos que un 38 por 100 de las camas pertenecen a hospitales construidos antes de 1900. La proporción es realmente preocupante en los hospitales mentales ( 46 por 100) $y$ asilos (44 por 100) que por distintos indicadores se revelan como centros más deficientes.

\section{Enseñanza Primaria}

Si a los niños (de seis a trece años) no matriculados sumamos los que probablemente aparecen matriculados dos veces y asisten irregularmente a clase, tendremos una definición más estricta de niños que no reciben regularmente ningún tipo de enseñanza y que. según nuestros cálculos, basados en datos oficlales, sobrepasan

"Si bien el problema de falta de unidades escolares era muy grave al inicio del I plan de Desarrollo, al término del mismo em. pieza a ser una auténtica vergüenza nacional la existencia de un déficit de más de 23.000 unidades escolares que afectan a cerca de un millón de niños sin escuela o escolarizados deficientemen. ten (1).

\section{Bachillerato}

En 1960-61 se calculaba en España un total de 474.057 alumnos matriculados en el total de cursos de la enseñanza media. En 1967. 1968 esa cifra asciende a 1.092 .934 alumnos. Pero este crecimiento tan espectacular experimentado por el bachillerato se debe fundamentalmente al crecimiento del bachillerato elemental. En 1967-68. en efecto, se mantiene la misma proporción de bachilleres superio. res que en 1960-61: el 17 por 100 del total. Esto significa que el crecimiento, en numeros absolutos, ha sido mucho mayor en el bachillerato elemental que en el superior.

Como escribe C. Iglesias Selgas: "El crecimiento a nivel universitario no ha guardado correspondencia con el crecimiento a nivel de ensentanza media.. La desproporción entre el crecimiento de la enseñanza media y superior es uno de los estrangulamientos materiales que tiene nuestro sistema docenten.

(i) Intome ronsss 1970. pág. 049. 
Por otra parte, In diferencia, dentro del bachillerato elemental, entre Alava con tha lasa de escolartad de 71 por 100, y Huelva. con un 22 por 100, o Cuenca, con un 20 por 100 , no puede ser más dramática. Sólo doce provincias españolas, todas de la mitad Norte, tienen escolarizada a la mitad o más de su población, comprendida entre los once y diecisiete años. Dentro del bachillerato superior, las diferencias son también muy importantes: desde Alava, con una tasa de 24 por 100, a Huelva, con una de 4 por 100.

Si tenemos en cuenta conjuntanente los datos de escolarización primaria y bachillerato, es evidente que se dibuja cada día con mayor nitidez la línea hipotética que separa a las dos Españas, la desarrollada y la atrasada en el terreno educativo. Esta linea Irfa desde Salamanca hasta Alicante y dejaría con el Sur, en el campo de la España atrasada, a las cuatro provincias gallegas.

\section{Ensefianza Superior}

El crecimiento de la matrícula comienza a ser espectacular en 1960; en ese año se llega a los 77.123 estudiantes, o sea, 253 por 100.000 habitantes. Siete años más tarde, se ha duplicado esa cifra, la cual, al ritmo actual, llegará a los 383,000 en 1975 .

Más espectacular aún es el crecimiento de la matrícula total que caracteriza a los estudiantes de las Escuelas Especiales. Aun contando con una deficiente información thasta muy recientemente no se contabilizaban los alumnos del antiguo "Ingreso" en dichas Escuelas), vale la pena subrayar que todavía en 1950 no se habia llegado a la matricula de 3.000 , cuando se ha pasado ya la de 38.000 en 1967.

Está claro, pues, que ya desde ahora y en el próximo futuro habrá que hacer frente a tal número de alumnos, que, como no se empiece a preparar con criterios realistas profesorado y centros, el fracaso del sistema será espectacular y sus consecuencias imprevisibles.

\section{Igualdad de oportunidades en la enseñanza}

El porcentaje más alto de becarios de la Comisaria General de Protección Escolar to encontramos en la Formación Profesional Industrial: un 30 por 100 del total de alumnos en 1964-65, un 27 por 100 en 1965-66, un 22 por 100 en 1966-67.

Fuera de esa rama de la enseñanza, la proporción de becarlos de la Comisaria en el período $1965-67$ apenas llega al 10 por 100 y en algunos casos (Universidad y Escuelas Técnicas) no pasa del 5 por 100 . 
Además, aunque se aprecia un decidido incremento en la proporción de becarios desde 1961 a 1965, en los últimos años esa proporción se mantiene prácticamente constante o en descenso en la mayoría de las enseñanzas. Otro dato: sólo un 6 por 100, apro. ximadamente, de los estudiantes de Enseñanza Superior son hijos de obreros.

Salta a la vista que queda un camino muy largo desde esta situación actual a la plena gratuidad de la enseñanza que propugna la Ley en vigor de Reforma del Sistema Educativo.

\section{Investigadores}

Según datos de la OCDE, a la cabezá figura Estados Unidos, con el 3,7 por 100 de producto nacional bruto gastado en investigación (110 dólares por habitante) y a la cola, Grecia, España, Portugal y Turquía, con menos de 0,50 por 100 del PNB invertido en investigación (alrededor de un dólar por habitante). (La encuesta de la OCDE se refiere a catorce paises europeos más Canadá, Estados Unidos y Japón].

\section{Vivienda}

Según los cálculos de Pedro de Cuadra Echaide y Alejandro Pérez Manrique en su monografía "Demanda y acceso a la propie. dad de las viviendas", el déficit de viviendas en 1967 se elevaria a 881.177. A esto habría que añadir unos dos millones de viviendas que necesitan de reposición por antigüedad.

\section{Urbanismo.}

Segün José Martín Blanco en el libro "La infraestructura del urbanismo", "Hasta el año 2.000 es necesario urbanizar el doble de lo urbanizado a través de los tiempos y edificar otro tanto de lo edificado en España a lo largo de los siglos" (2).

(2) Para amplincion de los dalos ofrecidos, cue no pretenden ser sino ina muestra, podrla rerri. tir al lector a las mismes fuentes pot $\mathrm{m}$ t unilizactas $y$ de las que han sldo tomados: Informe FOESSA, 1970; Plas CCB, de Cáritas Española; Informe sotiológlco sobre la situaelón social en Madrid (FOESSA, 1967); Estructura Soctoeconómica de Andilucta Orfental, par José Cazorla l'érez; diversas monografías del 11 Plat de. Desarrollo. Los datos se refieren en su gran mayorfa a 1968.

En el anticuto que sigue, de 3. M. González. Estéfani, puede encontrar el lactor un tratarniento del lema eEquipamiento Colectivo en el campo de lo socto-culiurals. 